\title{
EFFECT OF THE FEED RATE AND DEPTH ON MACHINING COST IN CUTTING PROCESS
}

\author{
Milton F. Coba Salcedo ${ }^{1 *}$, Rafael Ramirez Restrepo ${ }^{2}$, Guillermo Valencia Ochoa ${ }^{3}$ \\ ${ }^{1}$ Materials Engineering and Manufacturing Technology Research Group - IMTEF, Universidad del Atlántico, \\ Carrera 30 Número 8 - 49, Puerto Colombia - Colombia \\ ${ }^{2}$ Mechanical Engineering Department, Mechanical Design and Maintenance Research Group, Universidad del \\ Atlántico, Carrera 30 Número 8 - 49, Puerto Colombia - Colombia \\ ${ }^{3}$ Efficient Energy Management Research Group, Universidad del Atlántico, Carrera 30 Número 8 - 49, Puerto \\ Colombia - Colombia \\ miltoncoba@mail.uniatlantico.edu.co
}

\begin{abstract}
In this paper we analyzed the effect of feed rate and depth parameters on machining costs in production. The process used was the turning of parts with cast iron base material. For this study, the feed rate between $0.2 \mathrm{~mm}$ and $0.8 \mathrm{~mm}$ and the depth in the range of $1 \mathrm{~mm}$ to $4 \mathrm{~mm}$ are varied, allowing to find parameters that affect the final finish of the part, such as the cutting speed and the working conditions of the machine. Other important parameters defined in this process are the process times that directly influence the final costs and how production can be maximized. With this paper is shown the increase in cost in the machinability of turning in a máximum production system.
\end{abstract}

Keywords - Feed Rate, depth, machining cost, cutting process.

\section{INTRODUCTION}

Foundryisoneof the most demanding and energy-intensive processes in which there are currently six different stages: casting, alloying, casting, pouring, solidification and finishing[1]. The casting process has not yet reached its full potential in limiting losses due to tilting, tipping, lost foam and other factors for the material [23].Therefore, this process clearly depends on the viscosity of the fluid, but if the demand includes the precise reproduction of mould details and overall dimensional accuracy, additional factors such as flow analysis affected by the rheological properties of the sludge, wetting, melting pressure and high temperatures should be considered, leading to a variety of part defects that affect subsequent machining processes to achieve the final finish[4-5].

If parts are defective it presents many challenges to operators and personnel involved in the production process, because the margin of error for a part's operating specifications is very limited[6], and if it is so imperfect it may reach an unrecoverable point, directly causing loss of money and time affecting the company's productivity[78].

In order to mitigate this problem a little, it has been proposed to analyze the operation ranges to which the specialized machinery and the production of parts must work, evaluating factors such as the cutting speed, the useful life of the parts for the final finish, the revolutions per minute of the machinery, among others[9]; presenting an area of efficiency where production gains are obtained at different advances and depths in the machining process[10].

The main contribution of this work is to present a methodology that analyzes the influential parameters in the production of the machining of the parts by turning, allowing to analyze the ranges in which a lathe must be operated so that there are no economic losses in the mass production of a specific part. Allowing the scientific community to focus on optimizing another stage ofthesmeltingprocess.

\section{METHODOLOGY}

The following is a description of the process and the fundamental equations for the analysis of costs and time in the turning process for grey foundries, allowing the identification of the parameters that have the greatest impact on this machining process.

\subsection{Process description}

In order to analyze step by step the possible options that were presented in the process, a flow diagram was proposed that allowed us to evaluate the description of the process as shown in Figure 1. 


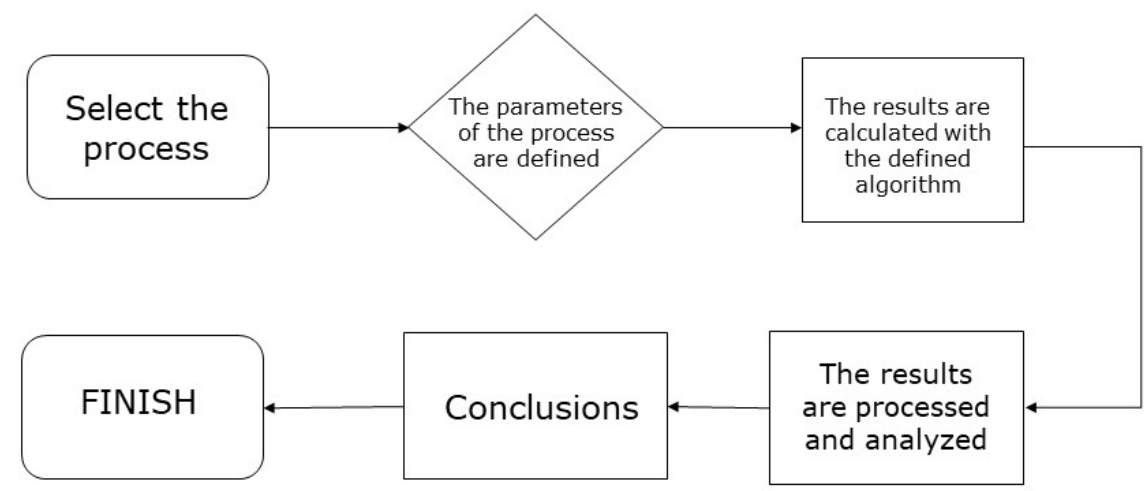

Figure 1. Flow chart diagram of the process.

\subsection{Fundamental Equations}

For the turning process in foundries it is necessary to analyze the following equations that allowed us to evaluate the operating costs for a production of specified parts. For the analysis of the minimum cost speed, input data such as the constant surface speed and the number of parts to be manufactured were provided. For a more detailed analysis the non-productive time should be provided as we will see in equation (1)

$$
\text { Non productive time }=N * \text { tnp } \text {. }
$$

Cutting time using equation (2)

$$
t c=\frac{\pi L}{a \cdot p \cdot V c \cdot 1000},
$$

where $\mathrm{L}$ is the part length, a is the feed rate, $\mathrm{p}$ is the penetration and $\mathrm{Vc}$ is the cutting speed.

The time of change will be analyzed by equation (3)

$$
\text { Time of change }=N a h * \operatorname{tr} f \text {, }
$$

where Nah is the number of sharpened parts needed to build the final part and trf is the resetting time of the edge.

The expenses generated by the operator and the machine per time unit are associated to $\mathrm{X}$ and the cost of the tool to Y. Therefore, to determine the cost per piece, equation (4) is proposed as follows

$$
C p=X \cdot t n p+X \cdot t c+\frac{N a h}{N}(X \cdot \operatorname{trf}+Y) .
$$

For the analysis proposed in this article, the machining cost per piece is a parameter that will be established according to the cutting speed, so the equation (5) was obtained.

$$
C p=X \cdot t n p+\frac{X \cdot K}{V}+\frac{N a h}{T_{1} \cdot V_{1}^{\frac{1}{n}}} \cdot V^{\frac{1-n}{n}} .
$$

Deriving equation (5) with respect to speed and equating it to zero, the lowest cost speed was obtained as equation (6)

$$
V m c=V_{1} \cdot\left(\frac{n}{1-n} \cdot \frac{X . T_{1}}{X \cdot t_{r f}+Y}\right)^{n}
$$

To determine the tool life at minimum cost, equation (7) is proposed

$$
T m c=\left(\frac{1-n}{n} \cdot \frac{X \cdot t_{r f}+Y}{X}\right)
$$

To calculate the maximum production speed it was proposed to calculate the tool life; from the time required to create a part, equation (8) is obtained

$$
t p=t n p+t c+\frac{N a h \cdot t r f}{N}
$$

By replacing the cutting time and the number of tools according to the cutting speed, the ratio between the production time and the speed is obtained. Therefore, the maximum production speed must be found to reduce the time it takes to manufacture a part, so equation (9) is obtained.

$$
V m p=V 1 \cdot\left(\frac{n}{1-n} \cdot \frac{T 1}{\operatorname{trf}}\right)^{n},
$$

by obtaining the ratio for tool life and cutting speed it is possible to find the minimum production time as shown in equation (10) 


$$
t m p=\frac{1-n}{n \cdot t r f}
$$

\section{RESULTS AND ANALYSIS}

For the analysis of this process, influential parameters such as the feed rate and cutting depth were analyzed, directly affecting the results such as the volume of the chip produced, the cutting time and the feed rate. Figure 2 shows the production behavior of a part as the feed rate increases showing a downward behavior in the cutting speed of 34\%, decreasing the desired process results significantly for maximum production. With respect to the final production of parts at minimum cost, the decrease in production is not so significant that it allows the desired results to be obtained at low speeds without the overwork that the machine may suffer.

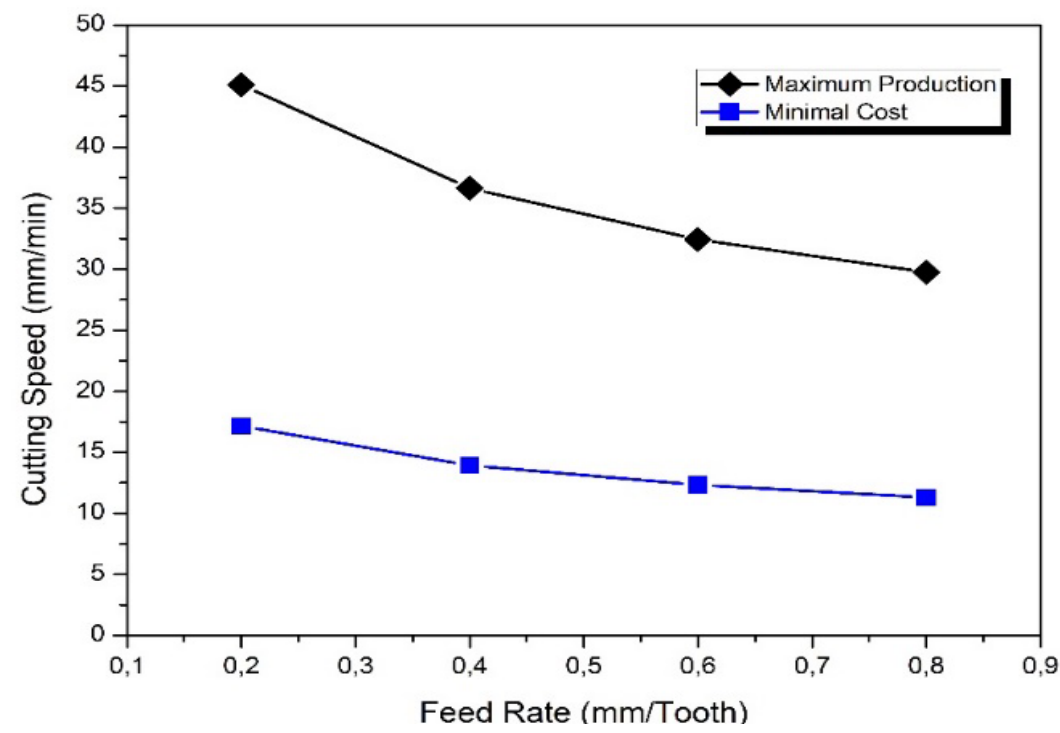

Figure 2. Cutting Speed performance respect the feed rate

Since wear on the part is proportional to many variables, it was possible to focus the study on the cost involved in cutting time and tooling in relation to the volume of shavings devastated by the part being manufactured. Figure 3 shows the amount of chip removed in the cutting cycle established for the part showing the significant increase in cutting time cost due to the energy and material variables used. For a cutting time range between 1.35 minutes and 1.55 minutes, the cost of the tool increases because the sharpening process for a batch of 1000 pieces in production is very repetitive, increasing the cost of the tool by $13.7 \%$ over the working time. The volume of chips is one of the most influential parameters in the cost of the process since the more devastated the part needs to reach its final finish, the higher the energy, tool and maintenance costs of the machinery used for this purpose, showing the direct effect on operating costs.

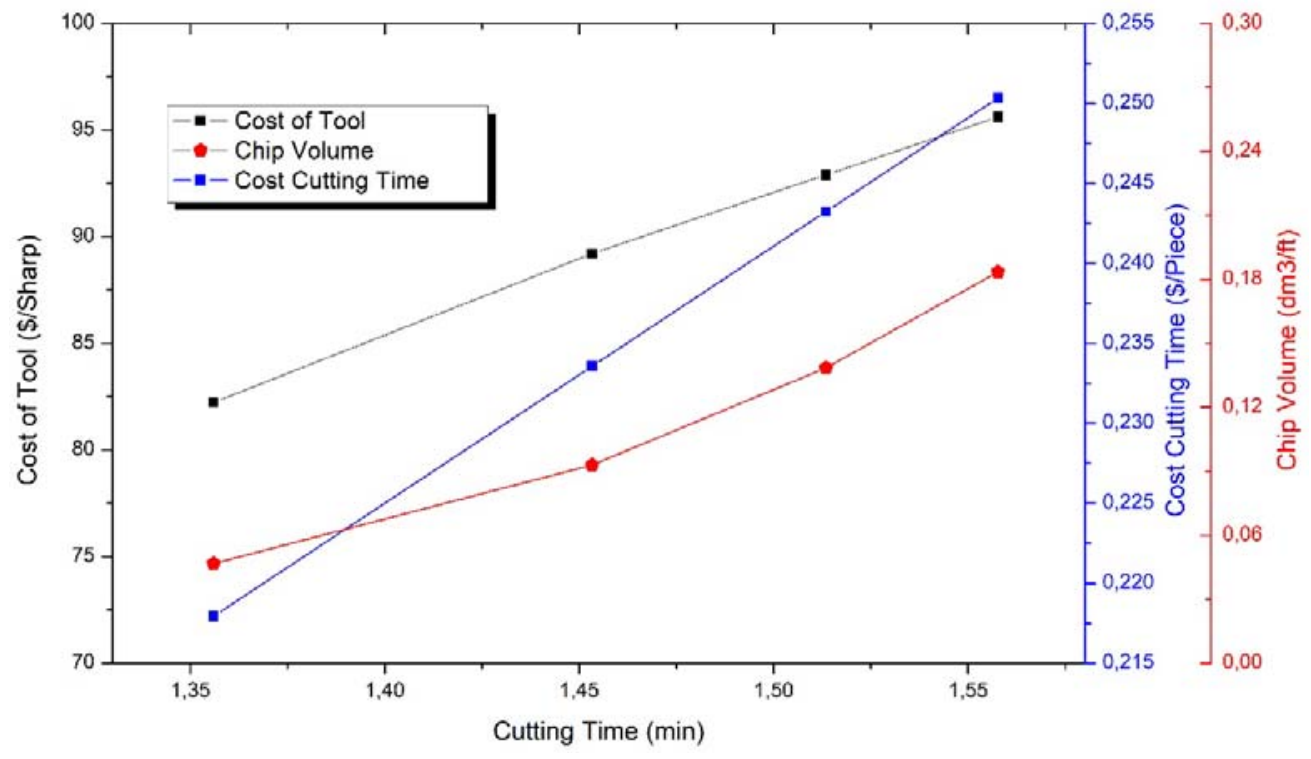

Figure 3. Performance of cutting time in the cost tool and the cost cutting time 
To analyze the effect of varying the depth of a part's manufacture, several parameters were analyzed, allowing the evaluation of the cutting time, the cutting speed, the machine rpm and the cost of the part's cutting time. In Figure 4(A) the increase in depth affects the cutting speed due to the forces exerted between the cutting tool and the manufacturing part, resulting in a decrease in unit development when the process layout is needed for máximum production. In Figure 4(B) due to the characteristics of surface castings the increase in depth between $1 \mathrm{~mm}$ and $2 \mathrm{~mm}$ causes the cutting time to increase significantly by $6.9 \%$. In Figure 4(C) it is possible to analyze the decrease in the RPM of the machine as the depth increases when the process configuration for maximum production increases, due to the direct effects that can be produced in the finishing of the part and its properties producing residual stresses due to sudden changes in temperature. In Figure 4(D) the cost of cutting time per piece increases proportionally to the finishing sizes required by the design. For the analysis in a 1000 piece lot the unit cost of those that require a depth of $1 \mathrm{~mm}$ showing a cost of $0.218 \$$ /Piece compared to $0.250 \$$ /Piece that requires a depth of $4 \mathrm{~mm}$, the costs increase due to the energy used by the machine, since more effort is needed to devastate the piece.
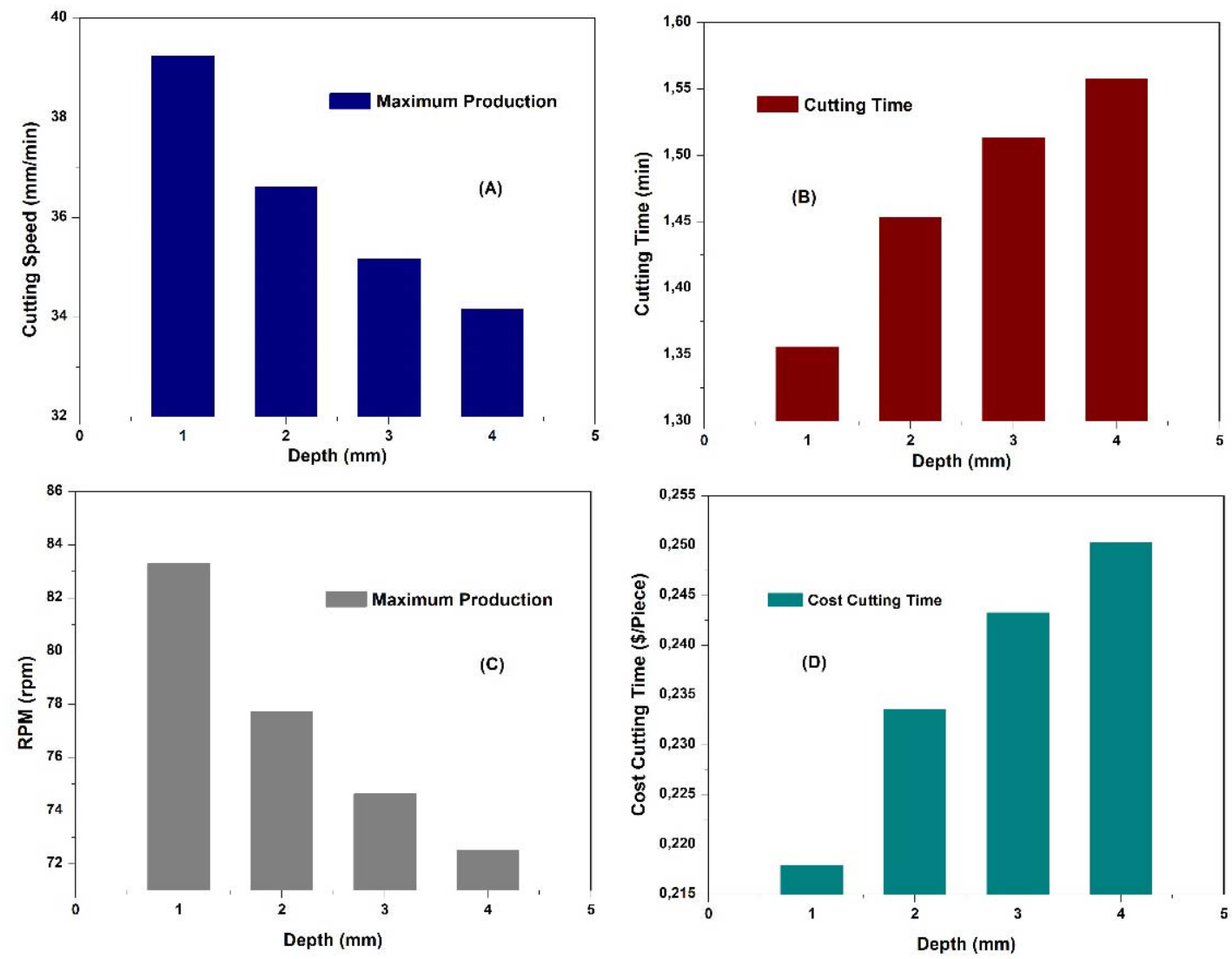

Figure 4. Performance of parameters for different depth in the process.

\section{CONCLUSIONS}

Thepreviousstudyallows us to conclude that an appropriate analysis to obtain exact calculations of the manufacturing costs of a batch of 1000 pieces can be carried out by analyzing the depth required in the standards of the piece, because the variation of this parameter allows us to analyze the times, materials and resources used in this machining process. The cost of the tool increases in the proposed work cycle, due to the fact that the process has a higher stock removal rate, depending on the depth at which the part must be finished.

\section{REFERENCES}

[1] K. Salonitis, B. Zeng, H. A. Mehrabi, and M. Jolly, “The Challenges for Energy Efficient Casting Processes,” Procedia CIRP, vol. 40, pp. 24-29, 2016.

[2] J. Campbell and J. Campbell, “Casting,” in Complete Casting Handbook, Elsevier, 2015, pp. 821-882.

[3] R. Lalbondre, P. Krishna, and G. C. Mohankumar, “An Experimental Investigation on Machinability Studies of Steels by Face Turning,” Procedia Mater. Sci., vol. 6, pp. 1386-1395, Jan. 2014.

[4] B. W. Darvell and B. W. Darvell, "Casting,” in Materials Science for Dentistry, Elsevier, 2018, pp. 484-498.

[5] “Casting alloys and foundry data,” in Metals Reference Book, Elsevier, 1976, pp. 1290-1395.

[6] S. Tooptong, K. H. Park, and P. Kwon, “A comparative investigation on flank wear when turning three cast irons,” Tribol. Int., vol. 120, no. October 2017, pp. 127-139, 2018.

[7] C. Saikaew, "An implementation of measurement system analysis for assessment of machine and part variations in turning operation," Measurement, vol. 118, pp. 246-252, Mar. 2018.

[8] P. Beeley and P. Beeley, “Casting design,” in Foundry Technology, Elsevier, 2001, pp. 362-442. 
[9] R. M. Lazzarin and M. Noro, "Energy efficiency opportunities in the production process of cast iron foundries: An experience in Italy,” Appl. Therm. Eng., vol. 90, pp. 509-520, Nov. 2015.

[10] N. Mardan and R. Klahr, "Combining optimisation and simulation in an energy systems analysis of a Swedish iron foundry," Energy, vol. 44, no. 1, pp. 410-419, 2012.

\section{AUTHOR PROFILE}

Guillermo Valencia Ochoa born in Barranquilla, Colombia. Is a full-time professor at the Universidad del Atlántico. Received a degree in Mechanical Engineering from Universidad del Norte, located in Barranquilla, Colombia in 2005. Master in Mechanical Engineering from Universidad del Norte, Barranquilla, Colombia in 2008. Ph. D in Engineering from the Universidad PontificiaBolivariana, Medellin, Colombia in 2014. He is an assistant professor of the Mechanical Engineering Program, Specialization in Energy Efficient Management and Master in Energy Management at Universidad del Atlántico.

Milton Coba Salcedo born in Barranquilla, Colombia. Is a full-time professor at the Universidad del Atlántico. Received a degree in Mechanical Engineering from Universidad del Atlántico, located in Barranquilla, Colombia in 2001. Ph. D in mechanical engineering from Universidad Politecnica de Cataluña, España in 2012. He is an associate professor of the Mechanical Engineering Program.

Rafael Ramírez Restrepo born in Barranquilla, Colombia. Is a full-time professor at the Universidad del Atlántico. Received a degree in Chemical Engineering from Universidad del Norte, located in Barranquilla, Colombia in 1991. Master in Mechanical Engineering from Universidad del Norte, Barranquilla, Colombia in 2013. Nowadays, is studying a Ph. D in Energy in Universidad de la Costa, Barranquilla, Colombia. 